\title{
3D Printing of UV-Curable Polyurethane Incorporated with Surface-Grafted Nanocellulose
}

\author{
Denesh Mohan ${ }^{1,2} \mathbb{D}^{\circ}$, Mohd Shaiful Sajab ${ }^{1,2, * \mathbb{C}}$, Hatika Kaco ${ }^{3}$, Saiful Bahari Bakarudin ${ }^{4}$ and \\ An'amt Mohamed Noor ${ }^{5}$ \\ 1 Research Center for Sustainable Process Technology (CESPRO), Faculty of Engineering and Built \\ Environment, Universiti Kebangsaan Malaysia, Bangi 43600, Malaysia; denesh.mohan@gmail.com \\ 2 Department of Chemical \& Process Engineering, Faculty of Engineering and Built Environment, \\ Universiti Kebangsaan Malaysia, Bangi 43600, Malaysia \\ 3 Kolej GENIUS Insan, Universiti Sains Islam Malaysia, Bandar Baru Nilai 71800, Malaysia; \\ hatikakaco@usim.edu.my \\ 4 Institute of Microengineering and Nanoelectronics (IMEN), Universiti Kebangsaan Malaysia, \\ Bangi 43600, Malaysia; saifulbahari@ukm.edu.my \\ 5 Advanced Materials Research Cluster, Faculty of Bioengineering and Technology, \\ Universiti Malaysia Kelantan, Jeli Kampus, Jeli 17600, Malaysia; anamt@umk.edu.my \\ * Correspondence: mohdshaiful@ukm.edu.my; Tel.: +60-3-8921-6425
}

Received: 26 September 2019; Accepted: 2 December 2019; Published: 3 December 2019

check for updates

\begin{abstract}
The recognition of nanocellulose has been prominent in recent years as prospect materials, yet the ineffectiveness of nanocellulose to disperse in an organic solvent has restricted its utilization, especially as a reinforcement in polymer nanocomposite. In this study, cellulose has been isolated and defibrillated as cellulose nanofibrils (CNF) from oil palm empty fruit bunch (EFB) fibers. Subsequently, to enhance its compatibility with UV-curable polyurethane (PU)-based resin, the surface hydrophilicity of CNF has been tailored with polyethylene glycol (PEG), as well as reduced graphene oxide (rGO). The dispersibility of reinforced modified CNF in UV-curable PU was examined through the transmittance interruption of resin, chemical, and mechanical properties of the composite printed using the stereolithographic technique. Evidently, the enhanced compatibility of modified CNF and UV-curable PU was shown to improve the tensile strength and hardness of the composites by $37 \%$ and $129 \%$, respectively.
\end{abstract}

Keywords: additive manufacturing; cellulose nanofibrils; nanocomposites; nanoindentation; stereolithography

\section{Introduction}

As the world's second largest producer of palm oil products, Malaysia had an oil palm plantation area of 5.85 million hectares in 2017-an increase of $0.7 \%$ from the 5.81 million hectares in the previous year [1]. In tandem with the production of crude palm oil, the oil palm industry produces two forms of biomass waste, namely wastes from the mill and wastes from the field [2]. Even though large amounts of biomass are produced from the abovementioned agricultural waste, only $10 \%$ of the same is used as an alternative raw material in biocomposite-based industries, fertilizers, animal feeds, chemical derivatives, etc. [3]. It is estimated that in the mills, $23 \%$ of oil palm empty fruit bunches (EFB) are produced per ton of fresh fruit bunches [4]. Oil palm EFB is usually left as waste in the palm oil mill or used as boiler fuel for steam generation. Such use, however, has created an environmental pollution problem. Being rich in lignocellulose, there is huge potential for the production of nanocellulose, particularly for nanocomposite materials as reinforcing filler for the polymer industry, electronics, and also for biomedical purposes [5]. 
Oil palm EFB mainly consists of lignin, hemicelluloses, and cellulose, the last of which is the most abundant natural polymer worldwide [6]. The molecules of polymers like cellulose, hemicellulose, lignin, extractives, and pectin are responsible for the physical and mechanical properties of lignocellulosic materials [7]. Being a natural composite material, lignin binds the strands as well as the fibrils. Cellulose content and microfibrillar angle will determine the properties of the lignocellulosic fibers [8]. Therefore, the strengths of the fibers are dependent on the fibrillary structure, microfibrillar angle, and cellulose content [9]. Oil palm EFB fibers have sufficient strength and Young's modulus to be used as biocomposites. As cellulose is also a carbohydrate polymer which consists of repeating units of $\beta$-D-glucopyranose joined together by $\beta$-1, 4-glycosidic linkage bonds, it possesses the suitable properties of the biodegradable polymer [10]. Up to now, the utilization of cellulose is still expanding from the conventional injection molding to the additive manufacturing of composites.

Despite the fused deposition modelling (FDM)-based technique being widely used due to the inexpensive machine and materials, the quality of surface finish and mechanical properties of these printed materials are limited in comparison with other additive manufacturing techniques and typical manufacturing processes [11,12]. Apart from this technique, stereolithography is the most common technique for the creation of a computer-designed virtual three-dimensional object to be "printed" into a solid object [13]. This technique typically used UV-curable resins consisting of oligomers, monomers (which act as diluents), photo-polymerization initiators, co-initiators (spectral sensitizers, reducing agents, etc.), and various additives such as stabilizers, antioxidants, plasticizers, as well as pigments [14]. The majority of commercial light-cured resins are based on free radical-cured acrylic compounds (acrylates), which constitute the most versatile curing systems concerning properties of the products (monomers/oligomers) available in the market. Meanwhile, the thermoset nature of stereolithography-fabricated parts, along with their high crosslink density, results in brittle fractures with poor elongation properties [15].

Cellulose to cellulose nanofibrils (CNF) show a promising natural fiber for the reinforcement of polymer composites $[8,16,17]$. However, the highly hygroscopic nature of nanocellulose requires water-dispersible polymer matrices. The poor ability of nanocellulose to disperse in organic solvents has led to the separation of the matrix and fiber phases in the polymer nanocomposites [16]. Although lignocellulose is compatible with the hydrophilicity-hydrophobicity of cellulose/hemicellulose and lignin in nature, this unique feature is unlikely to manifest after fractionation owing to slight physicochemical changes in the isolated cellulose [18]. However, with the proper surface modification of nanocellulose (e.g., acetylation, polymer grafting) when acetylated cellulose was added to nitrile butadiene rubber, the mechanical properties of the compatibilized nanocellulose can significantly improve polymer nanocomposite material [19]. Furthermore, the introduction of polyethylene glycol (PEG) as an interfacial agent specifically prevents the agglomeration and allows the dispersion of the CNF for a homogeneous structure [20]. Alternatively, the hydrophobicity of reduced graphene oxide (rGO) can also be used to cover the hydroxyl group of cellulose and disperse well with the hydrophobic solvent [21].

Thus, this study has attempted to determine the extent of improvement of the mechanical properties for UV-curable polyurethane (PU)-based 3D-printed products by enhancing the compatibility of CNF as a reinforced material in the resin composition. CNF, which has been isolated and defibrillated from oil palm biomass of EFB fibers, was modified with PEG and rGO as compatibilizer and surface modifier. In-depth analysis of the chemical interactions between CNF, PU resin, and the modified CNF was performed and correlated with the tensile strength, Young's modulus, and the hardness of the printed composites. 


\section{Materials and Methods}

\subsection{Materials}

Oil palm EFB fibers procured from Szetech Engineering Sdn Bhd (Selangor, Malaysia) were milled and sieved at desired sizes of 106 to $500 \mu \mathrm{m}$. Preparation of cellulose isolation and the defibrillation processes were done using formic acid, 90\%, hydrogen peroxide, 30\%, sodium hydroxide, and iron (II) sulfate heptahydrate received from Merck, Darmstadt, Germany. While the surface-grafted CNF were formulated using PEG with an average $\mathrm{M}_{n}$ of 4000 (Linear formula, $\left.\mathrm{H}\left(\mathrm{OCH}_{2} \mathrm{CH}_{2}\right) \mathrm{nOH}\right)$ (Sigma-Aldrich, Darmstadt, Germany), synthesized reduced graphene oxide with graphite flakes (Ashbury, Inc., Ruckersville, VA, USA), phosphoric acid, 85\%, potassium permanganate, 99.9\%, hydrogen peroxide, 30\%, and sodium borohydride (Merck, Darmstadt, Germany). In 3D printing, commercial UV-curable resin was used with a composition of 45-47 wt\% polyurethane acrylate, 34-36 wt\% morpholine, and 15-17 wt\% tripropylene glycol diacrylate (Wanhao Precision Casting Co. Ltd. (Jinhua, China)), and isopropyl alcohol (Merck, Darmstadt, Germany) was used to remove the residual resin on the $3 \mathrm{D}$-printed samples.

\subsection{Isolation and Defibrillation of Cellulose}

The isolation of cellulose was performed in accordance with the protocol of a previous study [22,23]. In further detail, oil palm EFB were reacted with formic acid $(90 \% \mathrm{w} / \mathrm{v})$ at a $1: 30$ weight ratio at $95{ }^{\circ} \mathrm{C}$ for $2 \mathrm{~h}$. The experiments were performed in three-necked flat-bottomed flasks equipped with a condenser. Using a digital hotplate magnetic stirrer, the reagents were stirred at $800 \mathrm{rpm}$ (MSH-20D, Daihan Scientific, Gangwon-do, Korea). Subsequently, the supernatant and pulp were separated via vacuum filtration (MVP 10, IKA, Staufen, Germany). The pulp was then bleached with $\mathrm{NaOH}(2 \mathrm{wt} \%)$ and $\mathrm{H}_{2} \mathrm{O}_{2}(2 \mathrm{wt} \%)$ to degrade lignin and hemicellulose. Catalytic oxidation was performed to further purify to cellulosic pulp fraction. Specifically, a low concentration of $\mathrm{H}_{2} \mathrm{O}_{2}(2 \% \mathrm{w} / \mathrm{v})$, along with $10 \mathrm{mg} / \mathrm{L}$ $\mathrm{Fe}(\mathrm{II})$, was added to the reaction mixture and incubated at $90^{\circ} \mathrm{C}$ for $24 \mathrm{~h}$. The chemical residues were then removed by thorough washing with deionized water. From there, the extracted cellulose was kept in a $4{ }^{\circ} \mathrm{C}$ refrigerator overnight. Next, the purity and yield of the cellulose were closely monitored according to the National Renewable Energy Laboratory (NREL) standard. Chemical analysis was then performed to further characterize the cellulose.

To yield CNF via mechanical shearing, $0.7 \mathrm{wt} \%$ of cellulose solution was fibrillated using a high-speed blender at 37,000 rpm (Vitamix 5200, Vitamix, OH, USA) for $30 \mathrm{~min}$ in the presence of a control cycle. The temperature was consistently maintained at $70{ }^{\circ} \mathrm{C}$ throughout the process to prevent the hydrolysis of cellulose.

\subsection{Surface Modification of Cellulose Nanofibrils}

PEG was used to reduce the hydrophilicity of the CNF in order to improve their dispersibility in the resin matrix. Specifically, $0.5 \mathrm{wt} \%$ of PEG 4000 was dissolved in ethanol solution and added to the CNF solution with reference to the CNF content, after which the mixture was homogenized using an homogenizer for 30 min (T 25 Ultra-Turrax, IKA, Staufen, Germany). In the preparation of rGO, graphene oxide (GO) was prepared via Hummers' method with slight modifications. First, oxidation was carried out by mixing of $\mathrm{H}_{2} \mathrm{SO}_{4}(400 \mathrm{~mL})$, graphite flakes $(3 \mathrm{~g})$, and $\mathrm{KMnO}_{4}(18 \mathrm{~g})$, after which the mixture was stirred for 3 days using a magnetic stirrer to ensure the completion of graphite oxidation, as denoted by a color change from dark purplish-green to dark brown. Next, $\mathrm{H}_{2} \mathrm{O}_{2}(27 \mathrm{~mL})$ solution was added to the mixture to terminate the oxidation. Concurrently, the color of the mixture changed to bright yellow, indicating that the GO was highly oxidized. The resulting GO was washed thrice with $\mathrm{HCl}$ solution $(1 \mathrm{M})$ and ten times with deionized water until the $\mathrm{pH}$ of the product was in the range of 4 to 5 . Washing was performed using a centrifugation technique, whereby the CNF solution was mixed with $10 \mathrm{wt} \%$ GO solution using homogenizer for 30 min (T 25 Ultra-Turrax, IKA, Staufen, 
Germany), after which $\mathrm{NaBH}_{4}$ was added to the $\mathrm{CNF} / \mathrm{GO}$ mixture and heated at $80{ }^{\circ} \mathrm{C}$ for $60 \mathrm{~min}$ to yield $\mathrm{CNF} / \mathrm{rGO}$.

\subsection{Resin Composition for Stereolithography}

Commercial resin-based polyurethane was mixed vigorously with surface modified CNF with their respective proportions using homogenizer for $30 \mathrm{~min}$ (T 25 Ultra-Turrax, IKA, Staufen, Germany). As a reference, PU was homogenized with $0.005 \mathrm{wt} \%$ of PEG, equivalent to the PEG comprised in PU-1\%CNG/PEG and $0.001 \mathrm{wt} \%$ of rGO, equivalent to the rGO comprised in PU-1\%CNF/rGO. The mixture was then added to digital light-processing (DLP) 3D printer system (Duplicator D7 Plus, Wanhao, Jinhua, China), with a $405 \mathrm{~nm}$ UV lamp as a curing agent. The STL file model was followed by standard tensile specimen according to the ASTM D638 Type IV. The density was measured by the dimension and weight of printed samples. Meanwhile, each of the five printed layers was exposed for $70 \mathrm{~s}$. The final product was then washed in an isopropyl alcohol solution to remove the excessive polyurethane resin prior to further cure under UV light of wavelength $405 \mathrm{~nm}$. Meanwhile, the kinetics of the curing process was determined in terms of the weight of solid formed per minute. Briefly, $7 \mathrm{~g}$ of the resin with modified CNFs was added in the 3D-printed mold with similar dimensions to the standard tensile specimen and was exposed with a $405 \mathrm{~nm}$ UV lamp on the top of the 3D printer projector. The cured specimen at a determined time, $t$, was washed with isopropyl alcohol solution and the weight was recorded.

\subsection{Characterization}

The functional groups were characterized using Fourier transform infrared spectroscopy (FTIR, Bruker, Billerica, MA, USA) at a resolution of $1 \mathrm{~cm}^{-1}$ in a wavelength range of $650-4000 \mathrm{~cm}^{-1}$. In addition, $\mathrm{CNF}, \mathrm{CNF} / \mathrm{PEG}, \mathrm{CNF} / \mathrm{rGO}$, and $\mathrm{GO}$ had their morphological structures analyzed via transmission electron microscopy (TEM) (CM12 Philips, Eindhoven, Netherlands). The crystalline regions of the samples were evaluated via X-ray diffractometry (XRD) (Bruker D8 Advance, Bruker, Billerica, MA, USA). Furthermore, the transmittances of the PEG and rGO-modified polyurethane resins were measured using an SP-300SRB UV Spectrophotometer. Thermal properties of the samples were measured using a differential scanning calorimeter (Shimadzu/DSC50, Japan) under a nitrogen atmosphere. The viscosity of the resin was examine using Brookefield Ametek D1 viscometer with spindle type DV1HA at $100 \mathrm{rpm}$. Samples $(5 \mathrm{mg}$ ) were hermetically sealed in an aluminum pan and a sealed empty pan was used as the reference. Samples were first heated to $300{ }^{\circ} \mathrm{C}$ at a heating rate of $10^{\circ} \mathrm{C} / \mathrm{min}$. On another note, the tensile strength and Young's modulus of the samples were determined using Instron®Electromechanical Universal Testing Systems 3300 Series at $500 \mathrm{~mm} / \mathrm{min}$ with a load cell of $1 \mathrm{kN}$. The high loading rates was chosen based on the reproducibility of results for tensile strength and compliance with the previous study [24,25]. The micrograph of the cross-section 3D-printed samples after tensile testing was observed by a field emission scanning electron microscope, FESEM (Merlin Compact, Zeiss Pvt Ltd., Oberkochen, Germany), and the element mapping was monitored by energy dispersive X-ray analysis, EDX (Oxford Instruments GmbH, Wiesbaden, Germany). Finally, the nanoindentation behaviors of the materials were determined using a Nano TestTM (Micro Materials, Wrexham, UK) with a maximum load of $5 \mathrm{mN}$. Five times for each parameter were repeated tensile test and nanoindentation analyses.

\section{Results and Discussion}

\subsection{Characterization of Surface-Grafted CNF}

Figure 1a shows the successful cellulose defibrillation, whereas the individual fibrils were measured at comparable diameters average of 5 to $20 \mathrm{~nm}$ [26]. Contrastingly, GO in Figure $1 \mathrm{~b}$ appeared as a semi-transparent sheet and looks unstable when morphology was observed in TEM. The disordered and unwrinkled structure was attributed to the non-removal of oxygen atoms and a high degree 
of exfoliation during oxidation [27]. The micrograph of CNF/PEG shown in Figure 1c presents the dispersibility of CNF with the PEG, while the trace of CNF under a thin layer of rGO was visibly present in Figure 1d [28]. Moreover, the modified CNF shows both the stability of interfacial agents and remains as individual fibrils.

In the chemical characteristic of isolated cellulose and CNF, Figure 2a indicates the absorption peaks at $3400 \mathrm{~cm}^{-1}$ due to the presence of hydroxyl groups and stretching of the saturated aliphatic C-H of lignin and cellulose. These results were generally in line with those of a recent study on cellulose derivatives [29]. Likewise, the absorption peaks around 2902 and $1058 \mathrm{~cm}^{-1}$ were attributed to the C-H and C-O stretching vibrations on cellulose and CNF respectively. Meanwhile, the significant peaks of PEG were observed around $2885 \mathrm{~cm}^{-1}$ due to aliphatic C-H stretching, at $1106 \mathrm{~cm}^{-1}$ due to C-O stretching, and at $1467,1342,962,843 \mathrm{~cm}^{-1}$ attributed to the $\mathrm{C}-\mathrm{H}$ vibration in the PEG skeleton [30]. FTIR spectra of rGO had absorption peaks at around 1605 and $1095 \mathrm{~cm}^{-1}$ due to recovery of $\mathrm{sp}^{2}$ lattice and C-O stretching respectively [31]. Additionally, CNF/rGO and CNF/PEG had characteristic absorption peaks, which were the same as those of CNF. This could be explained by the hypothesis that cellulose nanofibrils were merely combined with rGO and PEG by physical interactions without the formation of new functional groups.
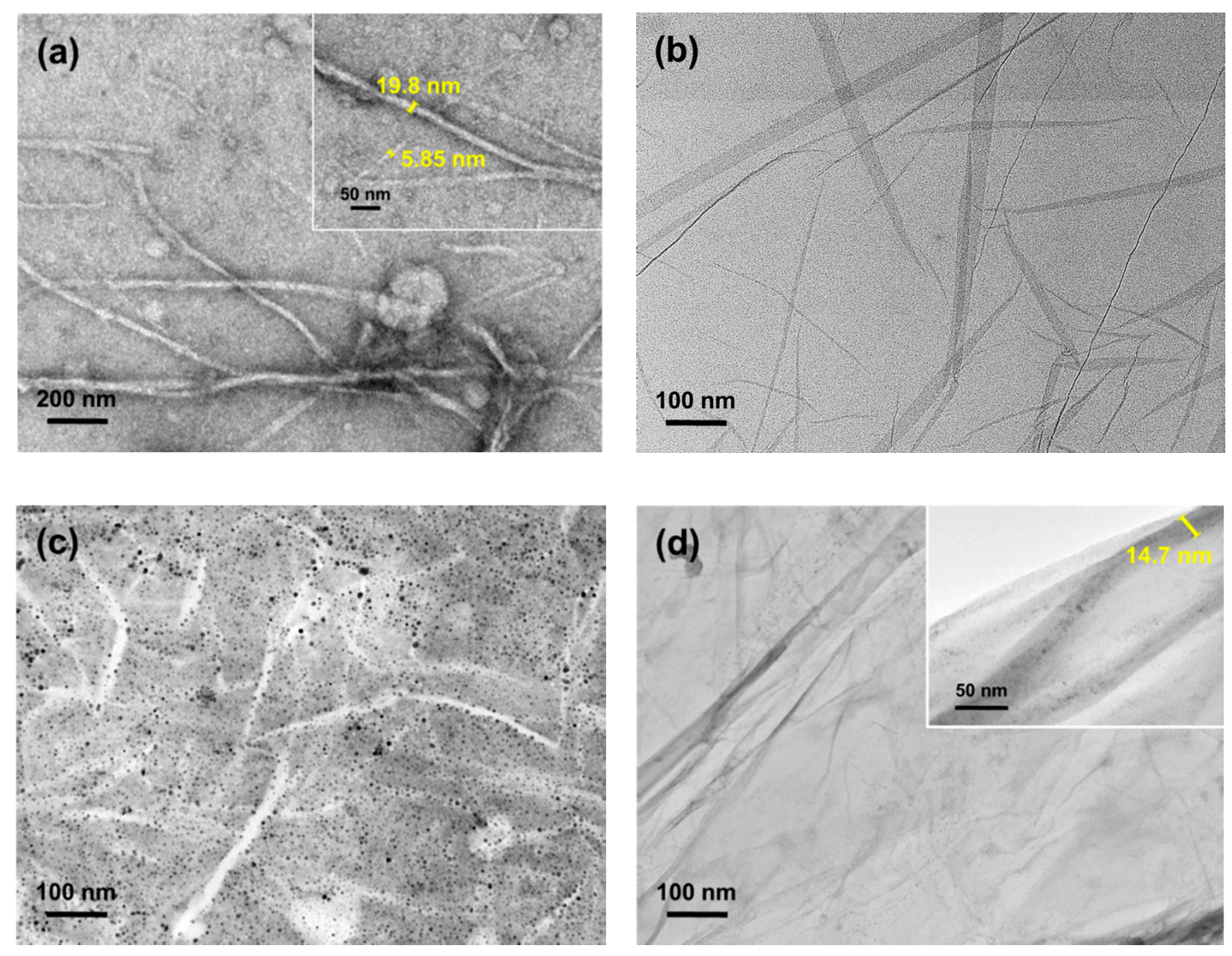

Figure 1. The micrograph of (a) unmodified cellulose nanofibrils (CNF), (b) reduced graphene oxide (rGO), (c) surface-grafted CNF/polyethylene glycol (PEG), and (d) surface-grafted CNF/rGO. 

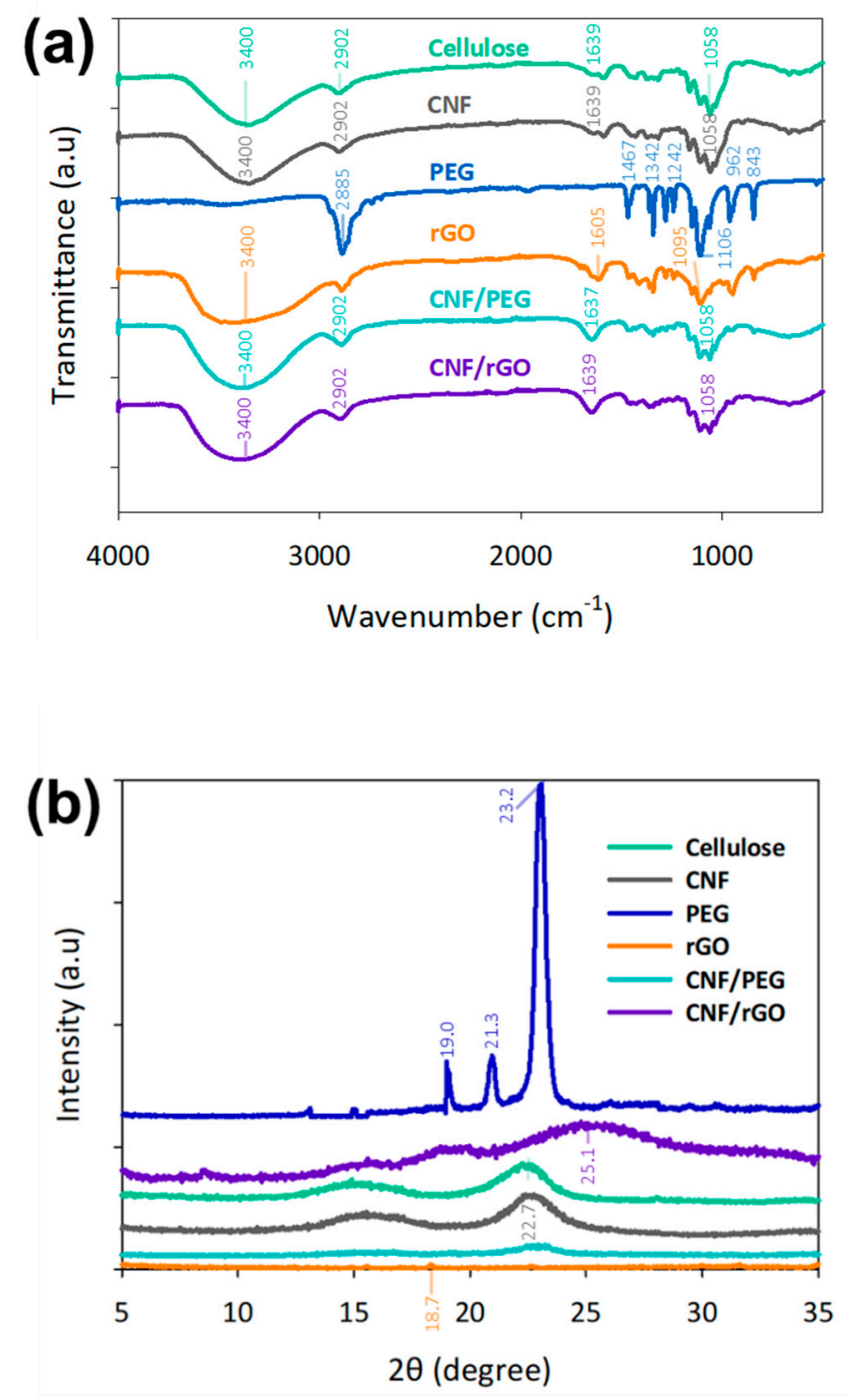

Figure 2. Chemical characterization of isolated cellulose, unmodified CNF, PEG, rGO, and surface-modified CNF/PEG and CNF/rGO on (a) Fourier transform infrared spectroscopy (FTIR) and (b) X-ray diffractometry (XRD) spectrum.

As shown in Figure $2 b$, the similarities of the patterns between both CNF and cellulose were maintained after the mechanical shearing. The crystallinity index increases after the treatment from $62.93 \%$ to $75.03 \%$ [32]. PEG 4000 showed sharp diffraction peaks at $2 \theta$ of $19^{\circ}, 21.3^{\circ}$, and $23.2^{\circ}$, thereby indicating the presence of crystalline regions. After the chemical reduction of GO to rGO, the ordered crystal structure of rGO was restored as a peak was observed at $18.7^{\circ}$ [33]. The weak and broad diffraction peak of rGO exhibits the interlayer spacing between graphene and restoration of graphitic structure after the chemical reduction [34]. CNF/PEG has a peak at $23.2^{\circ}$ owing to the presence of $\mathrm{PEG}$, while $\mathrm{CNF} / \mathrm{rGO}$ has a peak of around $25.1^{\circ}$, which indicates the reduction of oxygen-containing functional groups in GO structures [35].

\subsection{Transmittance and Curing Efficiency of Resin Composition}

Figure 3 shows the transmittance interruption at $405 \mathrm{~nm}$, which is attributable to the specific peak of polymerization for UV-curable PU resin [12]. The average transmittance of PU/rGO was higher than that of PU/PEG, which remains uninterrupted for the curing and polymerization process due to the thin layer of rGO shown in Figure 1d. However, the presence of CNF in the resin composition reduced the transmittance of selected wavelength significantly as the unmodified CNF decrease light 
transmission [26]. In addition, the effect of transmittance interruption of surface-grafted CNF on the curing efficiency of the resin composition was observed by UV exposure time on the top of the DLP projector (see Figure 3c). As a result, the PU resin, which contained a CNF modified rGO, was producing a higher solid formed per minute as a comparison with CNF modified PEG (see Table 1). The amount of PU-3\%CNF/rGO product generated (in terms of weight) was higher than that of PU resin despite the former having a lower absorbance. This phenomenon was due to the higher density of CNF relative to PU resin. Meanwhile, the amount of PU-5\%CNF/PEG produced was lower owing to its interruption of the transmitted wavelength.
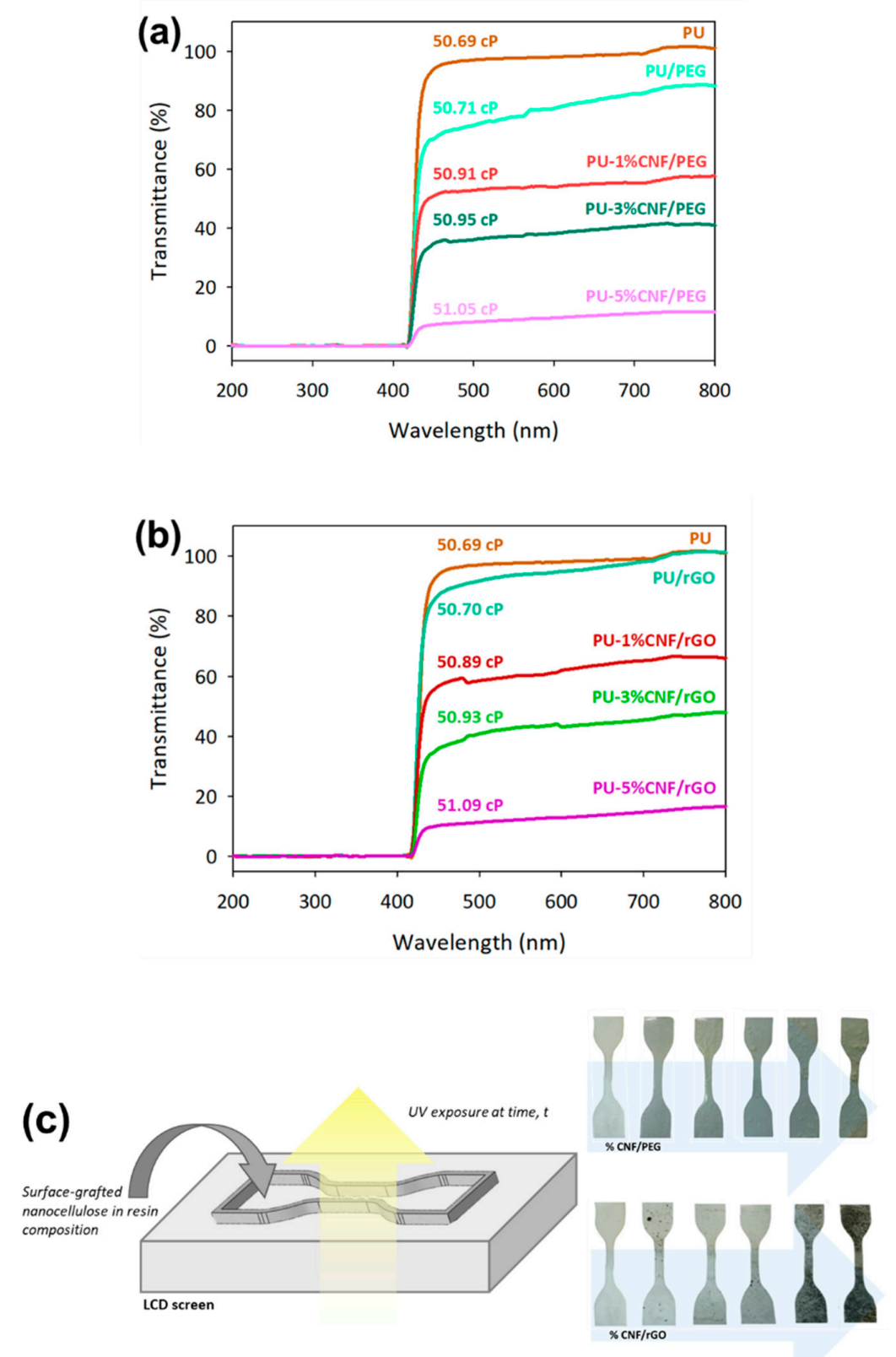

Figure 3. The transmittance of UV-curable polyurethane (PU)-based resin with the surface-grafted $\mathrm{CNF}$ composition of (a) CNF/PEG, (b) $\mathrm{CNF} / \mathrm{rGO}$, and (c) the curing process exposed in the 3D printer projector. 
Table 1. The kinetics of the curing process exposed in the 3D printer projector by the weight of solid formed per minute.

\begin{tabular}{|c|c|c|c|c|c|c|c|c|c|}
\hline \multirow{3}{*}{$\begin{array}{c}\text { Time, } t \\
\text { (min) }\end{array}$} & \multicolumn{9}{|c|}{ Weight of Sample After Curing at a Time, $t$ (g) } \\
\hline & \multirow[t]{2}{*}{ PU } & \multicolumn{4}{|c|}{ PU/PEG } & \multicolumn{4}{|c|}{ PU/rGO } \\
\hline & & $\begin{array}{c}0 \% \\
\text { CNF }\end{array}$ & $\begin{array}{c}1 \% \\
\text { CNF }\end{array}$ & $\begin{array}{l}3 \% \\
\text { CNF }\end{array}$ & $\begin{array}{c}5 \% \\
\text { CNF }\end{array}$ & $\begin{array}{c}0 \% \\
\text { CNF }\end{array}$ & $\begin{array}{c}1 \% \\
\text { CNF }\end{array}$ & $\begin{array}{l}3 \% \\
\text { CNF }\end{array}$ & $\begin{array}{l}5 \% \\
\text { CNF }\end{array}$ \\
\hline 1 & 1.08 & 1.08 & 1.09 & 1.14 & 1.06 & 1.11 & 1.14 & 1.21 & 1.10 \\
\hline 2 & 1.85 & 1.86 & 1.89 & 1.94 & 1.77 & 1.91 & 1.99 & 2.08 & 1.82 \\
\hline 3 & 2.06 & 2.07 & 2.16 & 2.21 & 1.96 & 2.12 & 2.27 & 2.36 & 2.01 \\
\hline 4 & 2.21 & 2.22 & 2.30 & 2.35 & 2.14 & 2.28 & 2.42 & 2.51 & 2.20 \\
\hline 5 & 2.36 & 2.37 & 2.41 & 2.46 & 2.30 & 2.43 & 2.53 & 2.63 & 2.37 \\
\hline 6 & 2.46 & 2.47 & 2.50 & 2.55 & 2.40 & 2.53 & 2.63 & 2.73 & 2.47 \\
\hline 7 & 2.52 & 2.53 & 2.56 & 2.61 & 2.46 & 2.60 & 2.69 & 2.79 & 2.53 \\
\hline 8 & 2.52 & 2.53 & 2.56 & 2.61 & 2.46 & 2.60 & 2.69 & 2.79 & 2.53 \\
\hline 9 & 2.52 & 2.53 & 2.56 & 2.61 & 2.46 & 2.60 & 2.69 & 2.79 & 2.53 \\
\hline
\end{tabular}

As a side note, the mixture of PU-based commercial resin with CNF exhibits a thick agglomeration with the inhomogeneous composition. The water moisture present in unmodified CNF on account of the hygroscopic nature of cellulose intervenes in the interface polymerization with hydrophobic polymers matrix such as PU $[8,36]$. In the addition of PEG and rGO as a compatibilizer, modified CNF was able to distribute well in the PU matrix. Hydrogen bonds could be formed between the PU matrix and CNF owing to the presence of PEG [20], whereby rGO layers acted as a moisture barrier which enabled the hydrophilic CNF particles to disperse well in the PU matrix without aggregates being formed $[27,37]$. Although the addition of surface-grafted CNF increased the viscosity of the resin, however, the tabulated data in Figure $3 \mathrm{a}, \mathrm{b}$ provided low significant changes $(\sim 2.4 \%)$ even at higher concentration of CNFs added in the resin.

\subsection{Characterization of $U V$-Cured Composites}

The chemical characterization of UV-cured composites was examined using FTIR, XRD, and DSC analyses, whereby the unmodified CNF and PU resin were used as reference materials (see Figure 4). In the FTIR spectrum, significant characteristic peaks of PU were still dominant, indicating there was no chemical interaction with polymer matrices upon addition of CNF/PEG and CNF/rGO, which highlighted the unaffected $\mathrm{C}=\mathrm{O}$ of polyurethane peak at $1761 \mathrm{~cm}^{-1}$. Theoretically, the $\mathrm{C}-\mathrm{O}-\mathrm{C}$ and terminal -OH of PEG were able to form hydrogen bonds or dipolar interactions with PU and CNF, connecting the polymeric linkage like a bridge [38].

In the XRD patterns, PU resin displayed only one diffuse and amorphous halo, indicating that no well-defined ordered structures existed. The XRD pattern intensity increases with the addition of $1 \%$ of CNF/PEG and CNF/rGO as the implementation of CNF disrupts the original uniform and makes the PU matrix more crystalline. The DSC plots in Figure $4 \mathrm{c}$ show the glass transition temperatures $\left(\mathrm{T}_{\mathrm{g}}\right)$ for PU, PU-1\%CNF/PEG, PU-1\%CNF/rGO are 58.2, 60.0, and $61.8^{\circ} \mathrm{C}$, respectively. This represents the temperature range in which the polymer substrate shifts from a stiff glass material to a smooth material [39]. The $T_{g}$ increases with the addition of surface-grafted CNF, which can be attributed to the fact that, as stated earlier, the crystallinity of the PU/CNF composite increased with the addition of $\mathrm{CNF}$, resulting in higher stiffness and rigidity of the composite [40]. 

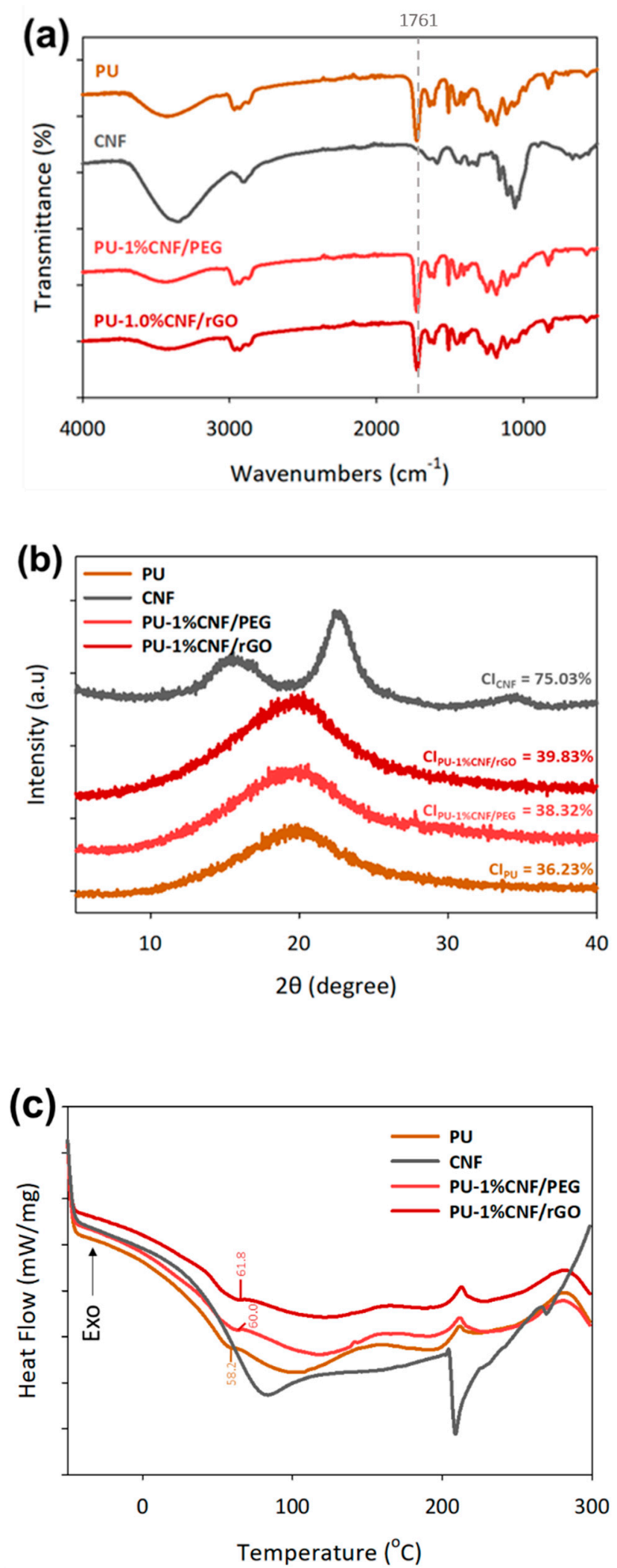

Figure 4. Characterization and comparison between the UV-cured composites and unmodified CNF and PU resin on (a) FTIR, (b) XRD, and (c) differential scanning calorimetry (DSC). 


\subsection{Mechanical Properties}

The dispersibility of the reinforced modified cellulose in UV-cured PU was investigated using tensile properties of the materials shown in Figure 5. As a reference, the addition of PEG and rGO to $\mathrm{PU}$ (wt \% equivalent of PEG and rGO contained in $1 \%$ of modified CNF) improved the tensile strength by $8.3 \%$ and $9.37 \%$, respectively. This could be attributed to the fact that the CNF/PEG and CNF/rGO facilitated the crystallization process of PU [41]. Alternatively, graphene is the polymer nanofiller of choice because its layered structural fillers have a large surface area (up to $2630 \mathrm{~m}^{2} / \mathrm{g}$ ) [42]. Thus, a lower loading of graphene improved the properties of the composite owing to its high aspect ratio [43].
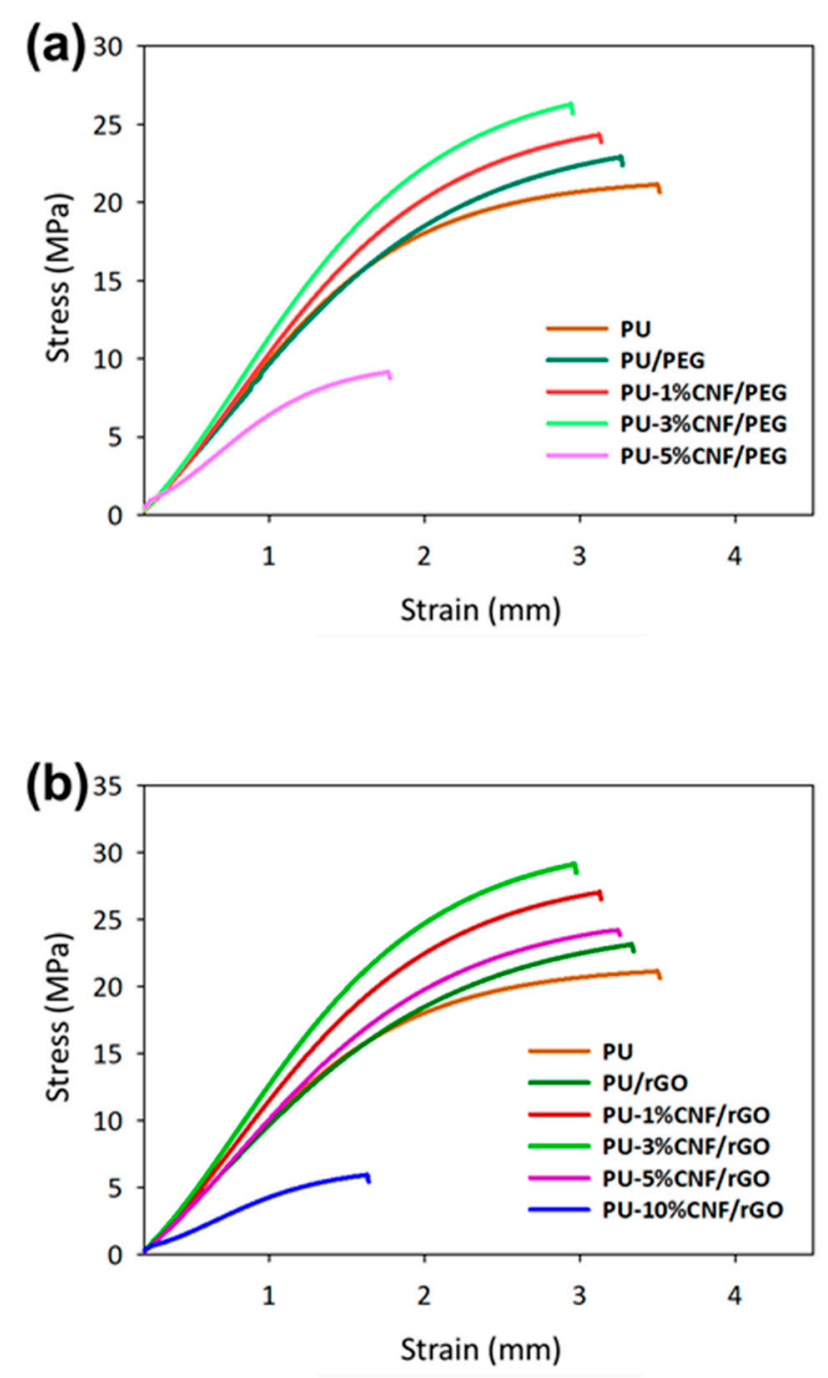

Figure 5. Stress-Strain curve of UV-cured PU and reinforced modified CNF with (a) PEG and (b) rGO.

Therefore, PU-3\%-CNF/PEG showed a $24 \%$ increment in its tensile strength relative to PU. Accordingly, the tensile strength of PU-3\%CNF/rGO was $37 \%$ and $11 \%$ better than those of $\mathrm{PU}$ and $3 \%-\mathrm{CNF} / \mathrm{PEG}$. Although the presence of PEG facilitated the interactions between the hydrophobic polymer and the hydrophilic CNF, rGO provided better removal hydrophilicity of CNF than PEG due to the higher density of carbon atoms on its surface $[20,44]$. rGO can nullify the natural hydrophilicity of CNF, thereby enabling the latter to disperse well in hydrophobic PU [45]. Likewise, previous studies noted an improvement in the mechanical properties of CNF-composites following the addition of CNFs of concentrations below $3 \mathrm{wt} \%$ [46]. Meanwhile, the loading of $5 \%$ modified CNF resulted in a decline in the tensile properties due to the generation of non-uniform stress transfer when the sample was under tension loading. The reason for this finding was when the filler loading exceeded $5 \mathrm{wt} \%$, 
the CNF particles started to aggregate in the polymer matrix and introduce more interfacial voids which reduced the tensile strength of the composite [47]. As a consequence, the entire nanocomposite could have acted as a stress concentrator and hence, the mechanical properties declined [48]. Moreover, a higher CNF loading interrupted the curing of the photocurable PU resin and the printed samples orientation is affected due to insufficient curing at higher CNF loading rate.

The tensile strength of the UV-cured composites was correlated with Young's modulus materials (see Table 2). Evidently, the addition of CNF/PEG and CNF/rGO improved the Young's modulus of the composite. However, a higher loading of filler-reinforcer (i.e., PU-5\% $\mathrm{CNF} / \mathrm{rGO}$ ) often resulted in particle agglomeration and, hence, a decline in Young's modulus. As per previous studies, Young's modulus of the PU improved 7-fold following the incorporation of $4 \mathrm{wt} \% \mathrm{GO}$ [49]. The incorporation of rGO instead of PEG in CNF enhanced the mechanical properties of the composite since rGO better nullified the hydrophilicity of $\mathrm{CNF}$, subsequently improving the dispersion and mechanical properties. The dispersibility of the modified CNF in the 3D-printed samples was supported with the morphological structure of cross-section 3D-printed samples after tensile testing and the elements mapping shows in Figure 6. The neat PU-based resin of 3D-printed samples shows a clean wide line and smooth surface with the composition of carbon, oxygen, and phosphorus. In the addition of $\mathrm{CNF}$, the oxygen composition increased owing to the rich hydroxyl groups of cellulose [26]. The mixture of PU and unmodified CNF shows a visible void of interfacial polymerization due to the large hydrophilic surface at the sites of cellulose chain and hydrophobic polymers matrix of PU (see Figure $6 \mathrm{~b}$ ) $[8,36]$. On the other hand, the modified CNF provided better dispersibility between PU and $\mathrm{CNF} / \mathrm{PEG}$ and $\mathrm{CNF} / \mathrm{rGO}$. The reinforcement of fibrillated cellulose can be obviously seen in the fracture of the composites.

On another matter, the UV-cured composites have been analyzed by nanoindentation with a maximum load of $5 \mathrm{mN}$. The loading-unloading curves of the sample were presented in Figure 7 . Following the addition of $\mathrm{CNF} / \mathrm{PEG}$ and $\mathrm{CNF} / \mathrm{rGO}$, the loading-unloading pattern showed a typical trend, unlike the stress-strain curve. Meanwhile, the depth of indentation decreased, with an increase in hardness. Concurrently, the curves were shifted to the left, indicating an improvement in hardness trend when the CNF percentage was increased [50]. With a hardness of $75.04 \mathrm{MPa}$ (i.e., a $129 \%$ increment from unmodified UV-cured PU), PU-3\%-CNF/rGO showed the greatest improvement in this parameter. Apparently, the enhancements of the hardness and elastic modulus of $\mathrm{CNF} / \mathrm{rGO}$-reinforced PU composites could have been due to the presence of strong interactions and bonds between the functional groups of rGO and the PU chains [51]. Furthermore, the hydrophilicity of CNF was better removed in the presence of rGO. The basis for this occurrence was that rGO was a better plasticizer than PEG, so it better facilitated interactions with PU. However, when the concentration of graphene was increased to $3 \%$, a trend which was similar to that of the stress-strain curve (i.e., a decline in hardness with an increase in loading) interrupted the curing behavior of the UV-cured PU and, hence, gave rise to defects in the orientation of the printed samples. 

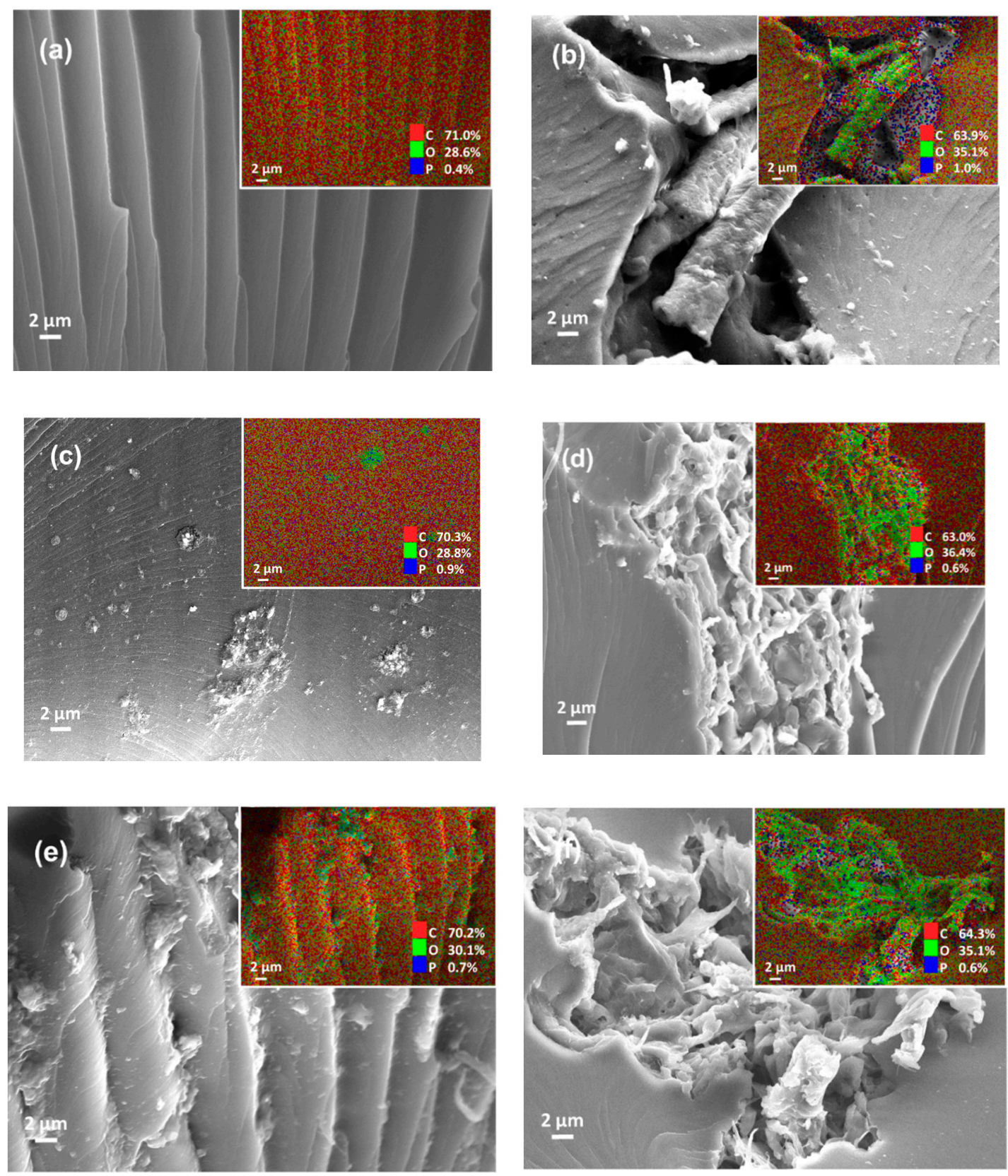

Figure 6. The micrograph and energy dispersive X-ray analysis (EDX) mapping of cross-section 3D-printed samples after tensile testing (a) PU, (b) PU-3\%CNF, (c) PU/PEG, (d) PU-3\%CNF/PEG, (e) $\mathrm{PU} / \mathrm{rGO}$, and (f) $\mathrm{PU}-3 \% \mathrm{CNF} / \mathrm{rGO}$. 

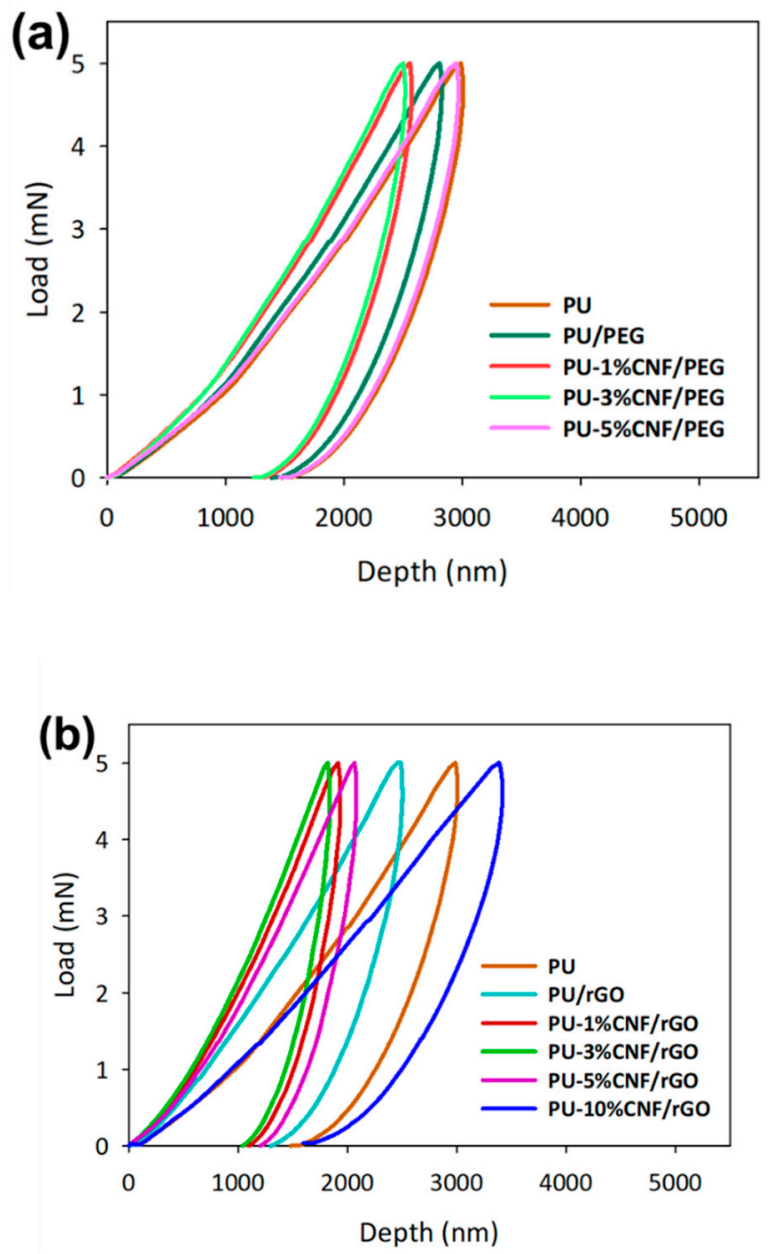

Figure 7. Nanoindentation displacement for UV-cured PU and reinforced with modified CNF with (a) PEG and (b) rGO.

Table 2. Young's modulus and loading-unloading behavior of UV-cured PU and reinforced with modified CNF with PEG and rGO.

\begin{tabular}{cccccc}
\hline Sample & $\begin{array}{c}\text { Tensile Strength } \\
\mathbf{( M P a}\end{array}$ & $\begin{array}{c}\text { Elongation } \\
\mathbf{( m m )}\end{array}$ & $\begin{array}{c}\text { Young's Modulus } \\
\mathbf{( M P a}\end{array}$ & $\begin{array}{c}\text { Max Depth } \\
\mathbf{( n m )}\end{array}$ & $\begin{array}{c}\text { Hardness } \\
\mathbf{( M P a})\end{array}$ \\
\hline PU & $21.24 \pm 0.21$ & $3.50 \pm 0.21$ & $9.79 \pm 0.15$ & $3008 \pm 15$ & $32.7 \pm 0.2$ \\
PU-PEG & $22.93 \pm 0.20$ & $3.26 \pm 0.14$ & $9.74 \pm 0.12$ & $2538 \pm 3$ & $40.2 \pm 0.2$ \\
PU-1\%CNF/PEG & $24.34 \pm 0.19$ & $3.14 \pm 0.15$ & $10.15 \pm 0.12$ & $2229 \pm 11$ & $52.8 \pm 0.1$ \\
PU-3\%CNF/PEG & $26.30 \pm 0.23$ & $2.94 \pm 0.19$ & $10.78 \pm 0.14$ & $2185 \pm 7$ & $59.6 \pm 0.3$ \\
PU-5\%CNF/PEG & $9.14 \pm 0.16$ & $1.76 \pm 0.23$ & $6.18 \pm 0.09$ & $2707 \pm 5$ & $32.5 \pm 0.1$ \\
PU-rGO & $23.15 \pm 0.19$ & $3.35 \pm 0.23$ & $10.43 \pm 0.13$ & $2502 \pm 8$ & $46.9 \pm 0.2$ \\
PU-1\%CNF/rGO & $27.07 \pm 0.30$ & $3.14 \pm 0.15$ & $10.88 \pm 0.16$ & $2000 \pm 12$ & $74.4 \pm 0.3$ \\
PU-3\%CNF/rGO & $29.16 \pm 0.26$ & $2.97 \pm 0.21$ & $12.41 \pm 0.18$ & $1934 \pm 8$ & $75.0 \pm 0.2$ \\
PU-5\%CNF/rGO & $24.21 \pm 0.21$ & $3.25 \pm 0.24$ & $9.93 \pm 0.12$ & $2018 \pm 6$ & $68.2 \pm 0.3$ \\
PU-10\%CNF/rGO & $5.94 \pm 0.12$ & $1.64 \pm 0.32$ & $3.44 \pm 0.09$ & $3419 \pm 7$ & $26.4 \pm 0.1$ \\
\hline
\end{tabular}

\section{Conclusions}

In this study, the dispersibility of modified CNF was exhibited through the enhanced mechanical properties, as the tensile strengths of PU-3\%CNF/rGO and PU-3\%CNF/PEG were 37\% and 24\% higher than UV-cured PU, respectively. Meanwhile, as per the outcomes of nanoindentations, $\mathrm{PU}-3 \% \mathrm{CNF} / \mathrm{rGO}$ had a hardness of $75.04 \mathrm{MPa}$ - $129 \%$ increase relative to that of unmodified photocurable PU. Likewise, PU-3\%CNF/PEG had an $82 \%$ increase in its hardness. However, the increment of CNF (more than 
$3 \mathrm{wt} \%)$ showed aggregation in the polymer matrix and introduces more interfacial voids, which reduced the mechanical properties of the composites.

Author Contributions: Conceptualization, M.S.S.; formal analysis, D.M. and S.B.B.; writing-original draft preparation, D.M., and M.S.S.; writing—review and editing, M.S.S., H.K. and A.M.N.; funding acquisition, M.S.S.

Funding: This research was funded by UNIVERSITI KEBANGSAAN MALAYSIA, grants number DIP-2017-017 and GUP-2018-104.

Conflicts of Interest: The authors declare no conflict of interest.

\section{References}

1. MPOB. Malaysian Oil Palm Statistics 2017; MPOB: Selangor, Malaysia, 2018; pp. 1-6.

2. Awalludin, M.F.; Sulaiman, O.; Hashim, R.; Nadhari, W.N.A.W. An overview of the oil palm industry in Malaysia and its waste utilization through thermochemical conversion, specifically via liquefaction. Renew. Sustain. Energy Rev. 2015, 50, 1469-1484. [CrossRef]

3. Palamae, S.; Dechatiwongse, P.; Choorit, W.; Chisti, Y.; Prasertsan, P. Cellulose and hemicellulose recovery from oil palm empty fruit bunch (EFB) fibers and production of sugars from the fibers. Carbohydr. Polym. 2017, 155, 491-497. [CrossRef] [PubMed]

4. Derman, E.; Abdulla, R.; Marbawi, H.; Sabullah, M.K. Oil palm empty fruit bunches as a promising feedstock for bioethanol production in Malaysia. Renew. Energy 2018, 129, 285-298. [CrossRef]

5. Lamaming, J.; Hashim, R.; Sulaiman, O.; Leh, C.P.; Sugimoto, T.; Nordin, N.A. Cellulose nanocrystals isolated from oil palm trunk. Carbohydr. Polym. 2015, 127, 202-208. [CrossRef] [PubMed]

6. Sun, S.; Sun, S.; Cao, X.; Sun, R. The role of pretreatment in improving the enzymatic hydrolysis of lignocellulosic materials. Bioresour. Technol. 2016, 199, 49-58. [CrossRef] [PubMed]

7. Misra, M.; Pandey, J.K.; Mohanty, A.K. Biocomposites: Design and Mechanical Performance; Woodhead Publishing: Cambridge, UK, 2015.

8. Monteiro, S.N.; Lopes, F.P.D.; Barbosa, A.P.; Bevitori, A.B.; Amaral Da Silva, I.L.; Da Costa, L.L. Natural lignocellulosic fibers as engineering materials-An overview. Metall. Mater. Trans. A 2011, 42, 2963-2974. [CrossRef]

9. Bourmaud, A.; Morvan, C.; Bouali, A.; Placet, V.; Perré, P.; Baley, C. Relationships between micro-fibrillar angle, mechanical properties and biochemical composition of flax fibers. Ind. Crops Prod. 2013, 44, 343-351. [CrossRef]

10. Kaco, H.; Zakaria, S.; Chia, C.H.; Sajab, M.S.; Saidi, A.S.M. Characterization of aldehyde crosslinked kenaf regenerated cellulose film. BioResources 2015, 10, 6705-6719. [CrossRef]

11. Kim, H.; Park, E.; Kim, S.; Park, B.; Kim, N.; Lee, S. Experimental study on mechanical properties of singleand dual-material 3D printed products. Procedia Manuf. 2017, 10, 887-897. [CrossRef]

12. Ligon, S.C.; Liska, R.; Stampfl, J.; Gurr, M.; Mülhaupt, R. Polymers for 3D printing and customized additive manufacturing. Chem. Rev. 2017, 117, 10212-10290. [CrossRef]

13. Catarino, S.; Lima, R.; Minas, G. Smart Devices: Lab-on-a-Chip; Elsevier Ltd.: Amsterdam, The Netherlands, 2016; ISBN 9780081007464.

14. Ligon-Auer, S.C.; Schwentenwein, M.; Gorsche, C.; Stampfl, J.; Liska, R. Toughening of photo-curable polymer networks: A review. Polym. Chem. 2016, 7, 257-286. [CrossRef]

15. Mondschein, R.J.; Kanitkar, A.; Williams, C.B.; Verbridge, S.S.; Long, T.E. Polymer structure-property requirements for stereolithographic 3D printing of soft tissue engineering scaffolds. Biomaterials 2017, 140, 170-188. [CrossRef] [PubMed]

16. Salehudin, M.H.; Salleh, E.; Muhamad, I.I.; Mamat, S.N.H. Starch-based biofilm reinforced with empty fruit bunch cellulose nanofibre. Mater. Res. Innov. 2014, 18, S6-322-S6-325. [CrossRef]

17. Abdellaoui, H.; Raji, M.; Essabir, H.; Bouhfid, R.; Qaiss, A. Mechanical behavior of carbon/natural fiber-based hybrid composites. In Mechanical and Physical Testing of Biocomposites, Fibre-Reinforced Composites and Hybrid Composites; Woodhead Publishing: Cambridge, UK, 2019; pp. 103-122.

18. Kumar, A.K.; Sharma, S. Recent updates on different methods of pretreatment of lignocellulosic feedstocks: A review. Bioresour. Bioprocess. 2017, 4, 7. [CrossRef] 
19. Taib, M.N.A.M.; Yehye, W.A.; Julkapli, N.M.; Hamid, S.B.O.A.A. Influence of hydrophobicity of acetylated nanocellulose on the mechanical performance of nitrile butadiene rubber (NBR) composites. Fibers Polym. 2018, 19, 383-392. [CrossRef]

20. Qu, P.; Gao, Y.; Wu, G.; Zhang, L. Nanocomposites of poly(lactic acid) reinforced with cellulose nanofibrils. BioResources 2010, 5, 1811-1823.

21. Yang, W.; Zhao, Z.; Wu, K.; Huang, R.; Liu, T.; Jiang, H.; Chen, F.; Fu, Q. Ultrathin flexible reduced graphene oxide/cellulose nanofiber composite films with strongly anisotropic thermal conductivity and efficient electromagnetic interference shielding. J. Mater. Chem. C 2017, 5, 3748-3756. [CrossRef]

22. Santanaraj, J.; Sajab, M.S.; Mohammad, A.W.; Harun, S.; Chia, C.H.; Zakari, S.; Kaco, H. Enhanced delignification of oil palm empty fruit bunch fibers with in situ fenton-oxidation. BioResources 2017, 12, 5223-5235. [CrossRef]

23. Sajab, M.S.; Mohan, D.; Santanaraj, J.; Chia, C.H.; Kaco, H.; Harun, S.; Kamarudin, N.H.N. Telescopic synthesis of cellulose nanofibrils with a stable dispersion of $\mathrm{Fe}(0)$ nanoparticles for synergistic removal of 5-fluorouracil. Sci. Rep. 2019, 9, 11703. [CrossRef]

24. Ibrahim, F.; Mohan, D.; Sajab, M.S.; Bakarudin, S.B.; Kaco, H. Evaluation of the compatibility of organosolv lignin-graphene nanoplatelets with photo-curable polyurethane in stereolithography $3 \mathrm{~d}$ printing. Polymers 2019, 11, 1544. [CrossRef]

25. Zhang, J.; Wang, Y.; Liu, C.; Feng, F.; Wang, D.; Mo, H.; Si, L.; Wei, G.; Shen, J. Polyurethane/polyurethane nanoparticle-modified expanded poly(tetrafluoroethylene) vascular patches promote endothelialization. J. Biomed. Mater. Res. Part A 2018, 106, 2131-2140. [CrossRef]

26. Chan, C.H.; Chia, C.H.; Zakaria, S.; Sajab, M.S.; Chin, S.X. Cellulose nanofibrils: A rapid adsorbent for the removal of methylene blue. RSC Adv. 2015, 5, 18204-18212. [CrossRef]

27. Sajab, M.S.; Chia, C.H.; Chan, C.H.; Zakaria, S.; Kaco, H.; Chook, S.W.; Chin, S.X.; Noor, A.M. Bifunctional graphene oxide-cellulose nanofibril aerogel loaded with $\mathrm{Fe}(\mathrm{iii})$ for the removal of cationic dye via simultaneous adsorption and Fenton oxidation. RSC Adv. 2016, 6, 19819-19825. [CrossRef]

28. Hou, M.; Xu, M.; Li, B. Enhanced electrical conductivity of cellulose nanofiber/graphene composite paper with a sandwich structure. ACS Sustain. Chem. Eng. 2018, 6, 2983-2990. [CrossRef]

29. Abouloula, C.N.; Rizwan, M.; Selvanathan, V.; Abdullah, C.I.; Hassan, A.; Yahya, R.; Oueriagli, A. A novel application for oil palm empty fruit bunch: Extraction and modification of cellulose for solid polymer electrolyte. Ionics 2018, 24, 3827-3836. [CrossRef]

30. Fu, X.; Kong, W.; Zhang, Y.; Jiang, L.; Wang, J.; Lei, J. Novel solid-Solid phase change materials with biodegradable trihydroxy surfactants for thermal energy storage. RSC Adv. 2015, 5, 68881-68889. [CrossRef]

31. Zhang, C.; Dabbs, D.M.; Liu, L.-M.; Aksay, I.A.; Car, R.; Selloni, A. Combined effects of functional groups, lattice defects and edges in the infrared spectra of graphene oxide. J. Phys. Chem. C 2015, 119, 18167-18176. [CrossRef]

32. Rahimi, M.K.S.; Brown, R.J.; Tsuzuki, T.; Rainey, T.J. A comparison of cellulose nanocrystals and cellulose nanofibers extracted from bagasse using acid and ball milling methods. Adv. Nat. Nanosci. Nanotechnol. 2016, 7. [CrossRef]

33. Saleem, H.; Haneef, M.; Abbasi, H.Y. Synthesis route of reduced graphene oxide via thermal reduction of chemically exfoliated graphene oxide. Mater. Chem. Phys. 2018, 204, 1-7. [CrossRef]

34. Vinodhkumar, G.; Ramya, R.; Potheher, I.; Cyrac Peter, A. Reduced graphene oxide based on simultaneous detection of neurotransmitters. Prog. Chem. Biochem. Res. 2018, 1, 40-49. [CrossRef]

35. Kuzmenko, V.; Wang, N.; Haque, M.; Naboka, O.; Flygare, M.; Svensson, K.; Gatenholm, P.; Liu, J.; Enoksson, P. Cellulose-derived carbon nanofibers/graphene composite electrodes for powerful compact supercapacitors. RSC Adv. 2017, 7, 45968-45977. [CrossRef]

36. Wang, L.; Okada, K.; Hikima, Y.; Ohshima, M.; Sekiguchi, T.; Yano, H. Effect of cellulose nanofiber (CNF) surface treatment on cellular structures and mechanical properties of polypropylene/CNF nanocomposite foams via core-back foam injection molding. Polymers 2019, 11, 249. [CrossRef] [PubMed]

37. Peng, X.; Wu, K.; Hu, Y.; Zhuo, H.; Chen, Z.; Jing, S.; Liu, Q.; Liu, C.; Zhong, L. A mechanically strong and sensitive CNT/rGO-CNF carbon aerogel for piezoresistive sensors. J. Mater. Chem. A 2018, 6, 23550-23559. [CrossRef] 
38. Xu, Z.; Li, J.; Zhou, H.; Jiang, X.; Yang, C.; Wang, F.; Pan, Y.; Li, N.; Li, X.; Shi, L.; et al. Morphological and swelling behavior of cellulose nanofiber (CNF)/poly(vinyl alcohol) (PVA) hydrogels: Poly(ethylene glycol) (PEG) as porogen. RSC Adv. 2016, 6, 43626-43633. [CrossRef]

39. Becker, H.; Locascio, L.E. Polymer microfluidic devices. Talanta 2002, 56, 267-287. [CrossRef]

40. Yang, Z.; Li, X.; Si, J.; Cui, Z.; Peng, K. Morphological, mechanical and thermal properties of poly (lactic acid) (PLA)/cellulose nanofibrils (CNF) composites nanofiber for tissue engineering. J. Wuhan Univ. Technol. Mater. Sci. Ed. 2019, 34, 207-215. [CrossRef]

41. Rahmani, H.; Najafi, S.H.M.; Saffarzadeh-Matin, S.; Ashori, A. Mechanical properties of carbon fiber/epoxy composites: Effects of number of plies, fiber contents, and angle-ply layers. Polym. Eng. Sci. 2013, 54, 2676-2682. [CrossRef]

42. Parizi, M.T.; Ebrahimi, G.R.; Ezatpour, H.R. Effect of graphene nanoplatelets content on the microstructural and mechanical properties of AZ80 magnesium alloy. Mater. Sci. Eng. A 2019, 742, 373-389. [CrossRef]

43. Park, Y.T.; Qian, Y.; Chan, C.; Suh, T.; Nejhad, M.G.; Macosko, C.W.; Stein, A. Epoxy toughening with low graphene loading. Adv. Funct. Mater. 2015, 25, 575-585. [CrossRef]

44. Chen, T.; Soroush, A.; Rahaman, M.S. Highly Hydrophobic electrospun reduced graphene oxide/poly (vinylidene fluoride-co-hexafluoropropylene) membranes for use in membrane distillation. Ind. Eng. Chem. Res. 2018, 57, 14535-14543. [CrossRef]

45. Zainuddin, M.F.; Raikhan, N.N.; Othman, N.H.; Abdullah, W.F.H. Synthesis of Reduced Graphene Oxide ( $r$ GO) Using Different Treatments of Graphene Oxide (GO); IOP Conference Series: Materials Science and Engineering; IOP Publishing: Bristol, UK, 2018.

46. Zhou, Y.; Pervin, F.; Jeelani, S.; Mallick, P.K. Improvement in mechanical properties of carbon fabric-epoxy composite using carbon nanofibers. J. Mater. Process. Technol. 2008, 198, 445-453. [CrossRef]

47. Venkatesh, A.; Thunberg, J.; Moberg, T.; Klingberg, M.; Hammar, L.; Peterson, A.; Müller, C.; Boldizar, A. Cellulose nanofibril-reinforced composites using aqueous dispersed ethylene-acrylic acid copolymer. Cellulose 2018, 25, 4577-4589. [CrossRef]

48. Bal, S.; Saha, S. Fabrication and Characterization of Carbon Nanofiber (CNF) Based Epoxy Composites; IOP Conference Series: Materials Science and Engineering; IOP Publishing: Bristol, UK, 2015.

49. Cai, D.; Jin, J.; Yusoh, K.; Rafiq, R.; Song, M. High performance polyurethane/functionalized graphene nanocomposites with improved mechanical and thermal properties. Compos. Sci. Technol. 2012, 72, 702-707. [CrossRef]

50. Yang, R.; Zhang, Q.; Xiao, P.; Jun, W.; Bai, Y. Two opposite size effects of hardness at real nano-scale and their distinct origins. Sci. Rep. 2017, 7, 6053. [CrossRef] [PubMed]

51. Gupta, T.K.; Singh, B.P.; Tripathi, R.K.; Dhakate, S.R.; Singh, V.N.; Panwar, O.S.; Mathur, R.B. Superior nano-mechanical properties of reduced graphene oxide reinforced polyurethane composites. RSC Adv. 2015, 5, 16921-16930. [CrossRef]

(C) 2019 by the authors. Licensee MDPI, Basel, Switzerland. This article is an open access article distributed under the terms and conditions of the Creative Commons Attribution (CC BY) license (http://creativecommons.org/licenses/by/4.0/). 